Ȧn. Génét. Sél. anim., I972, 4 (4), 569-592.

\title{
INFLUENCE OF FITNESS DETERIORATION ON SELECTION LIMITS $\left({ }^{1}\right)$
}

\author{
F. OROZCO \\ Departamento de Genética, \\ Inst. Nac. de Investigaciones Agronómicas, \\ Avenida de Puerta de Hierro, \\ Madrid 3, Spain
}

SUMMARY

After reviewing the principal causes and possible solutions of selection plateaus and giving the corresponding credit for such slowing process of response to the loss of variability when selection progresses, it is considered the importance of the action of natural selection on the problem and the relationship between fitness and selection limits, with the creation, in may cases, of unbalanced individuals when a narrow criterium is used for selection looking for specific productive traits.

From the data of a long selection pilot experiment with Tribolium castaneum comparing systems of selection in relation with the genotype-environment interaction, a study on the relationship between reproduction or fitness traits and response or limits to selection has been carried out. After presenting the response plots of selected lines showing its situation as far as a possible plateau is concerned, it was investigated the influence of the performance level of the selected trait - virgin females ovoposition - on the percentage of families and individuals which failed to reproduce or to live until adult stage from total matings. This study was carried out both as a regression of such percentages on generations of selection as well as on egg laying average in the corresponding generation and population.

Also, at the level of generations 33 to 35 , number of larvae, pupae and adults per family, at some specified date after mating, was recorded to set an estimation of viability, livability and precocity along with its correlations with egg laying and among them in order to study their interrelations. As the control populations reflect the original values for such relationships, it was possible to deduct the evolution of them when comparing different types of selections and populations more or less plateaued. Some interesting contrasts were found which are largely discussed.

Comparisons between intended and realized selection differentials through generations were also made, checking for the effect of natural selection against the artificial one and its implications on the selection limits discussed. This study completed the information for the general discussion included at the end of the presentation.

It was shown clearly the close relationship between level or performance of the selected character and the fitness traits studied, in the sense that natural selection was playing, as expected, an important role in slowing the selection responses through loss of reproductivity and livability. In connection with natural selection two types of action were analyzed, namely, when the trait

(1) Cet article a été présenté à la Réunion du Groupe de travail "Sélection et Testage " de la Féderation des Branches européennes de la W.P.S. A., Tours et Saint-Brieuc (France), 7 septembre I97I. 
is negatively correlated with the fitness and when apparently it is not related at all. This second point was the main objective discussed here in line with the results reported by other authors, because it was clearly shown, through the evolution of laying in fecundated females, that the selected character was peripherical to fitness.

\section{INTRODUCTION}

To explain or to understand selection limits, several causes are frequently invoked. The greater or lesser importance of each one will be different in each case and there are not, probably, situations with only one of them acting to stop selection gains.

Following, in some way, to LERNER (I958), these are some of the main causes :

- Surely, the most important one is loss of variability with fixation of alleles when the character be determined from purely additive effects, a situation difficult to be presented in the majority of quantitative characters. In this case " reverse selection " will not respond. But, generally, the loss of variability is not as simple as from purely allele fixation and its consequent loss of additive variance, because the selection program could be not able to get profit from the non-additive fraction of the total variance. This is the case when no response is obtained but calculations are still giving variance as existent. It could be simply high phenotypic variance due only to environmental effects and not to genetic ones; but the most frequent case is when some non-additive genetic variance exists, in dominant, overdominant or epistatic form.

- Change in the environment, of deterioration type, can be also a cause for limits to selection; this change being independent of, or because of, the selection program; as building up of pathogenic organisms, etc.

- More frequent are those cases due to genotype $\times$ environment interaction in which the effective selection presure is diminished and even annulated, as in cases where selected parents were not submitted to infections affecting later on to the offspring (selection for resistance to diseases) ; or when there are drastic changes in the environment through generations, acting in different directions.

- Probably, in very rare and special cases, recurrent mutations in opposite direction to that intended by the selection could be another cause.

- Still more important is the case when the selection is directed to multiple objectives as it is in the majority of practical breeding programs. In this case, it is normal to reach a situation where no more gains are obtained even though the different traits are still showing high figures for the $h^{2}$. This is because some of the traits are negatively correlated and it is impossible to improve them at the same time, arriving to high figures for all them. Example of this is the well known fact of selection in meat type birds where the genetic correlation between egg production and body weight, at least in highly selected lines, is negative ; even though the phenotypic correlation could be zero or nearly zero due to have a positive environmental correlation. This is also the case reported by DickERSon (1955) between egg production and egg weight. 
- Finally, there is the possible antagonism between artificial and natural selection, which can account for many plateaued populations and probably becomes an important factor in almost all programs of selection, acting earlier or later. And this we is the case in which we are interested in this presentation.

It is not intended here to treat or review the ways the breeder could have to break those plateaus, but summarily it is possible to say that :

a) If the main cause was the loss of variability through fixation, with some desirable aleles not present because they were lost in the random drift or because they were not present in the original population, only migration, through different systems, seems to be promissing ; as FALCONER (I970) crosses of plateaued populations after some generations of inbreeding and posterior breeding within crosses, or other more or less complicated schemes.

b) If the program was not using non-additive variation, other schemes of breeding could be tried, as reciprocal recurrent selection or related methods to benefit from overdominance and/or heterosis.

c) A promissing new way is also the study of the adequated environment where the character be better expressed in order to have a higher selection differential, or to get the $h^{2}$ increased. Genotype $\times$ environment interaction studies are being carried out in this direction; even by using selection under stress conditions.

d) Introduction of favorable aleles through mutation is just a theoretical possibility but not very promissing at the moment in animal breeding; though the ideas of MérAT (I97I) on this topic must be meditated because in some situations they could be useful.

e) If limits come from negative correlations or from natural vs. artificial selection, then, they are situations more difficult to treat with.

In regards with the last reason or cause for plateaued populations, $i$. $e$. natural vs. artificial selection, two types of action could be considered : First, when the selected character is negatively correlated with someone or several fitness' traits, it is obvious that natural selection will be a brake, and relatively soon the response will be slowed and even stopped because the selected fraction will not have enough offspring, and so, more and worse individuals will have to be taken, $i$. $e$. the selection differential will diminish and even will become zero. This type of action is well known and there are enough examples in the literature concerning with limits to selection. But, there is another type of action, more subtle, which is that considered in this work. When the selected character is neutral or even positively correlated with those fitness traits and the selection progresses easily, the character reaching such extremes which could be considered as theratological ones, it is also certain that some of the reproductive traits become deteriorated ; the reason being that the genetic correlation could have changed and diminished, going to negative figures, or due to other phenomena more complicated and related with the physiological equilibrium. It is not pretended here to say that in these cases the plateaus come from only this reason and not because of lack of variability in whatever be its form, but only to suppose that the deterioration of fitness traits can play a more or less mportant role in the fact.

Based on lines obtained through several generations of selection in a long expe- 
riment with Tribolium castaneum, studying the genotype-environment interaction and comparing different systems of selection (OROzCO, I969 and I970), certains measures and calculations have been done in order to investigate the possible deterioration of reproductive traits. It is not an exhaustive nor systematic study, but only a partial a posteriori analysis with the available data and with the results of some special evaluations obtained during the last three generations. Given the positive conclusions of this study, it seems worthwhile to complete it by evaluating other characters and parameters, not included here, working with a more adequated design based on the same selection experiment.

So the work presented here contains a first approach to test if the different lines selected present some deterioration in fitness and to discuss its implications with selection limits and with both types of action in natural vs. artificial selection related above ; being a consistent basis for a more complete and developed future study on the topic here discussed.

\section{MATERIAL AND METHODS}

This study of fitness characters was realized on the lines developed in a selection experiment with the insect Tribolium castaneum where the quantitative character considered was the egg laying rate of virgin females evaluated from the $7^{\text {th }}$ to the IIth days after the aduit emergence.

Types of selection, or populations, can be seen in table $\mathbf{r}$, along with the three types of lines developed, within each population type, when selecting for performance at three different temperatures. At the bottom of the table there is the number of generations of selection considered in this work for the different types of populations. Reciprocal recurrent selection (r.r.s.) has one

TABLE I

Types of populations and lines $\left({ }^{1}\right)$ selected for 4 days egg laying rate of virgin females and number of generations of selection when this study was performed

Types de populations et de lignées sélectionnées pour le taux de ponte des femelles vierges sur 4 jours et nombres de générations de sélection

\begin{tabular}{|c|c|c|c|c|c|}
\hline \multirow{2}{*}{$\begin{array}{l}\text { Selection for } \\
\text { performance } \\
\text { at }\end{array}$} & \multicolumn{2}{|c|}{$\begin{array}{l}\text { Within line } \\
\text { family selection }\end{array}$} & \multirow{2}{*}{$\frac{\text { No selection }}{\text { Controls }}$} & \multicolumn{2}{|c|}{$\begin{array}{c}\text { Reciprocal recurrent selection } \\
\text { (High laying) }\end{array}$} \\
\hline & High laying & Low laying & & Pure Lines & Crosses \\
\hline $\begin{array}{l}28^{\circ} \mathrm{C} \\
33^{\circ} \mathrm{C} \\
38^{\circ} \mathrm{C}\end{array}$ & $\begin{array}{l}A F \\
A N \\
A T\end{array}$ & $\begin{array}{l}B F \\
B N \\
B T\end{array}$ & $\begin{array}{l}C F \\
C N \\
C T\end{array}$ & $\begin{array}{l}R / S-F\left({ }^{2}\right) \\
R / S-N \\
R / S-T\end{array}$ & $\begin{array}{c}s R / r S-F\left({ }^{2}\right) \\
s R / r S-N \\
s R / r S-T\end{array}$ \\
\hline $\begin{array}{l}\text { Generations } \\
\text { of selection }\end{array}$ & 35 & 29 & 35 & 17 & 17 \\
\hline
\end{tabular}

(1) There were two replications of each line.

(2) $R$ et $S$ are reciprocals, as well as $s R$ and $r S$. 


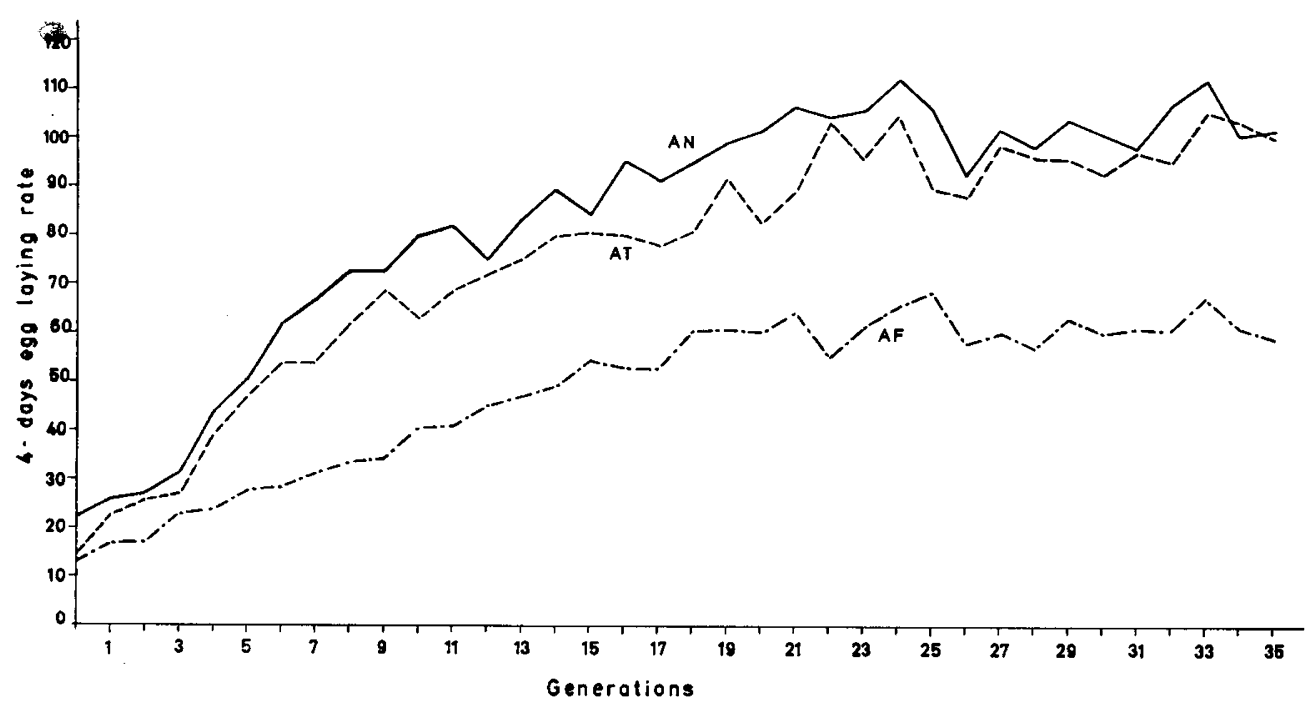

FIG. I. - Within line selection for high laying

Sélection intra-lignée pour une ponte elevée

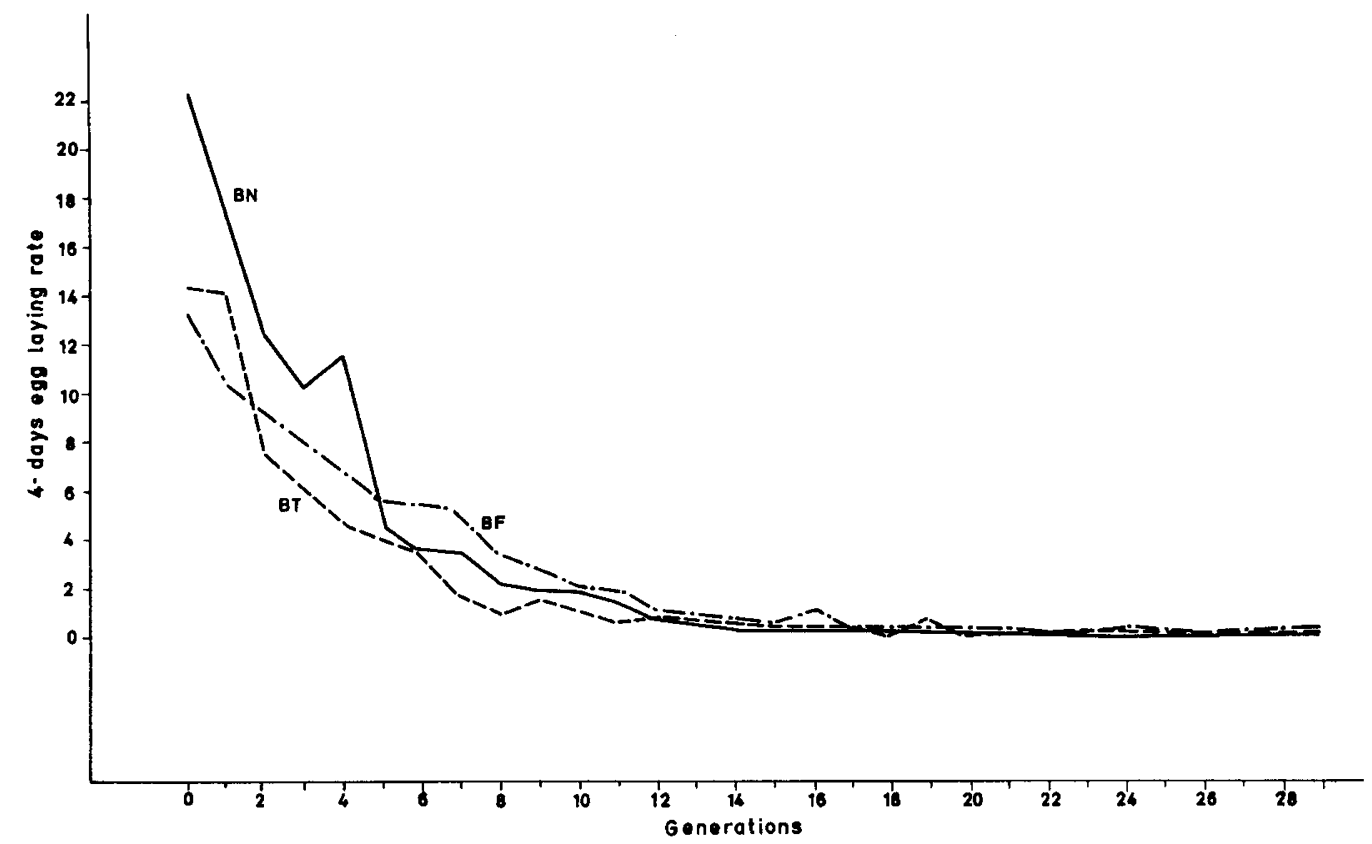

FIG. 2. - Within line selection for low laying Sélection intra-lignée pour une faible ponte 


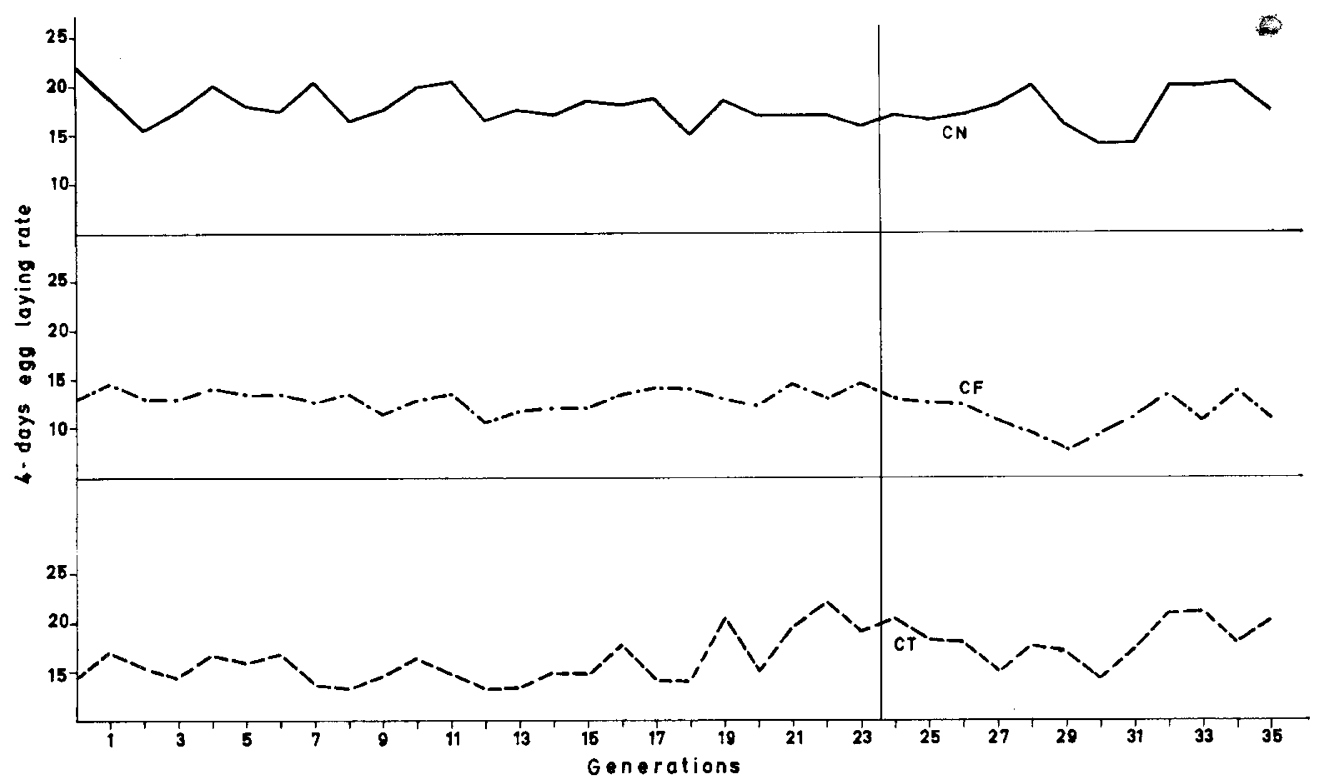

FIG. 3. - Control lines

Lignées témoins

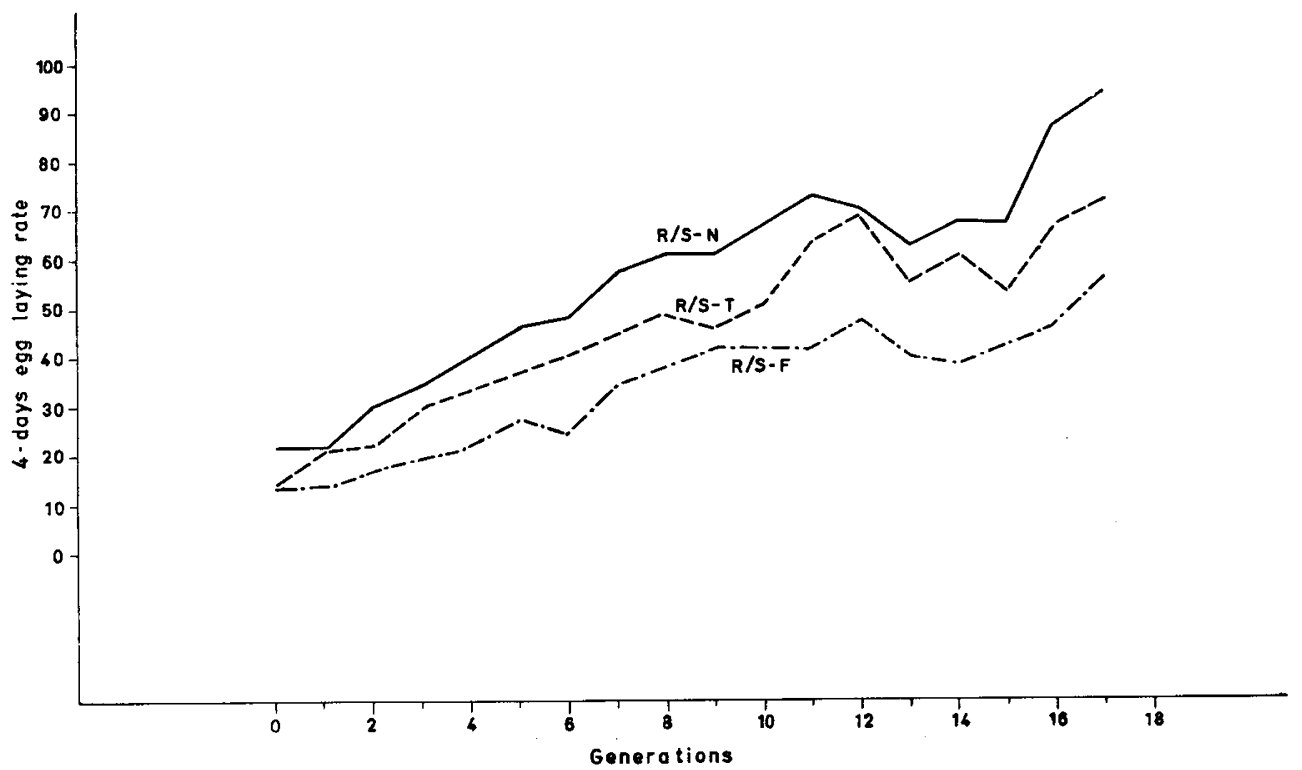

FIG. 4. - Reciprocal recurrent selection for high laying pure lines

Sélection réciproque et récurrente pour les lignées pures à ponte élevée 
half of generations than $A$ populations under within line selection (w.l.s.), because pure and crossed reproductions were performed in alternate generations. During the last part of the experiment and in order to reduce work, $B$ populations have been reproduced only every other generation of $A$ and $C$, due to the almost perfect response obtained when itryng to get zero egg laying.

Figures I through 5 give the selection response in each type, pooling replications in $A, B$ and $C$. In $r . \gamma . s$. both replications and reciprocals were pooled. Differences between reciprocal crosses were not significant, so the average figure is the best estimate of the response. In pure lines there were significant discrepancies between reciprocals, but as the objective of this study was not the comparison of systems of selection they are not considered separate.

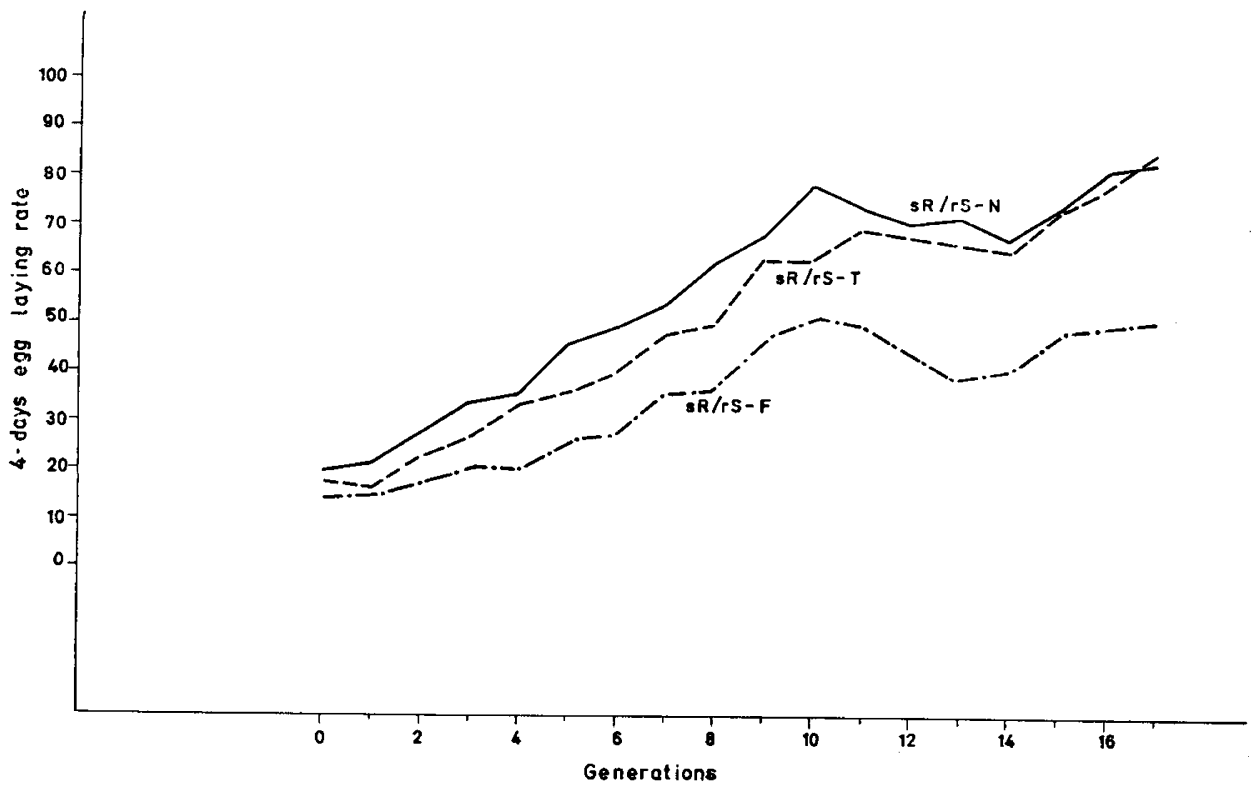

FIG. 5. - Reciprocal recurrent selection for high laying crosses

Sélection réciproque et récurrente pour les croisements à ponte élevée

With all these types of populations it is possible to evaluate the reproductive traits studied in relation with different types of responses : No response in controls $(C)$; a very positive response for high laying with w.l.s., that in the last generations seems to have reached a clear plateau $(A)$; a very positive response for low laying through w.l.s. with a definite plateau due to a physical impossibility, but still with some little variability $(B)$; and a reasonable good response as yet far from a plateau, with less number of generations of selection and with the possibility to discriminate between pure lines $(R / S)$ or crosses $(s R / r S)$ in the r.r.s.

No mention is given here to particular details of material and methods utilized which can be seen in the two above mentioned works containing the first part (2o generations) of the experiment. It is interesting to note, however, because it concerns with the objective of this study, that the mating of selected individuals was done in single pairs (one male to only one female), so the families are only of full sibs ; and that the development of larvae, as well as the rest of the life cycle, was at the normal temperature $\left(33^{\circ} \mathrm{C}\right)$, using only the high $\left(3^{\circ} \mathrm{C}\right)$ and the low $\left(28^{\circ} \mathrm{C}\right)$ ones during the egg laying test in lines $\mathrm{T}$ and $\mathrm{F}$ respectively.

Studies carried out here include the analysis of the following traits, always in connection with the larger or smaller response to selection, $i . e$. comparing the values of such traits in the different lines and populations :

a) Mating failures when no offspring is found in the corresponding vial the day of sexing (2 Ist after mating).

b) Number of individuals per mating found the above mentioned day of sexing. This total number of individuals (larvae + pupae + adults) can be expressed in terms of total matings 
done or in terms of the successful matings; the last being a better measure independent of the mating failures.

c) Precocity in the development of larvae can be measured by the relative proportion of larvae, pupae and adults found on that total number of individuals.

\section{RESUL'TS}

Most of calculations refered in this part were done at the level of individual replications (and also of reciprocal lines or crosses in r.r.s.), but in order to simplify the presentation, only are listed here the averaged or pooled values. Separated values for lines $N, F$ and $T$, selected at different temperatures, are not included in this chapter, but only the averaged values for them within each type of population (type of selection), due to the fact that the differences between lines are not pretended to be discussed here as not being very pertinent on the basic argument of this work.

\section{Evolution of failures with the selection progress}

For each line and replication of the above mentioned populations and for each generation, the percentage of failures from mating to egg laying test period was calculated. These failures were evaluated in two ways : (i) number of families totally lost and (ii) number of females lacking from the theoretical ones intended to be tested.

\section{TABLE 2}

\section{Linear regression of failures from mating to pupae stage} on egg laying average in each generation

Régression linéaire des échecs reproductifs, du stade accouplement au stade pupe, sur le taux de ponte moyen à chaque génération

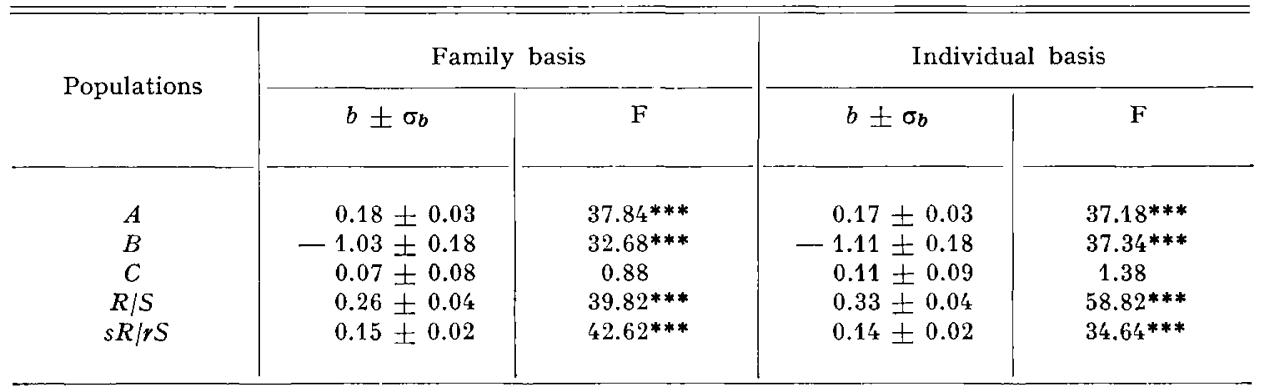

*** Significant at 0.001 level.

Linear regressions of these values on average egg laying and on generation serial number were calculated. Tables 2 and 3 present the results of such analyses including the regression coefficient with its standard error and the $F$ value for testing significance of such coefficient being different from zero. 
In these tables it is shown that failure of families or individuals grows significantly with generations of selection and with response to selection. In this last case $B$ populations give a negative slope, as it must be expected due to the selection for less number of eggs, instead of positive coefficients as in $A, R / S$ or $s R / r S$. Regression of controls $(C)$ on laying is not different from zero because there were not important changes in these lines. The significant figure, though small, for the regression on generations, must be due to some slight increase in failures after generation 23 when

\section{TABLE 3}

Linear regression of failures from mating to pupae stage on generations of selection

Régression linéaive des échecs reproductifs, du stade accouplement au stade pupe, sur les générations de sélection

\begin{tabular}{|c|c|c|c|c|}
\hline \multirow{2}{*}{ Populations } & \multicolumn{2}{|c|}{ Family basis } & \multicolumn{2}{|c|}{ Individual basis } \\
\hline & $b \pm \sigma_{b}$ & $\mathrm{~F}$ & $b \pm \sigma_{b}$ & F \\
\hline$A$ & $0.33 \pm 0.07$ & $24.77 * * *$ & $0.35 \pm 0.06$ & $29.55 * * *$ \\
\hline$B$ & $0.58 \pm 0.09$ & $43.43 * * *$ & $0.63 \pm 0.09$ & $50.91 * * *$ \\
\hline$C$ & $0.05 \pm 0.02$ & $8.76^{* *}$ & $0.12 \pm 0.02$ & $33.09 * * *$ \\
\hline$C^{\prime}(\mathbf{1})$ & $-0.03 \pm 0.02$ & $2.96\left(^{2}\right)$ & $-0.03 \pm 0.02$ & $2.96\left({ }^{2}\right)$ \\
\hline$R / S$ & $0.67 \pm 0.14$ & $21.23^{* * *}$ & $0.86 \pm 0.15$ & $31.95 * * *$ \\
\hline$s R / r S$ & $0.42 \pm 0.10$ & $17.76 * * *$ & $0.36 \pm 0.10$ & $13.33^{* * *}$ \\
\hline
\end{tabular}

Significant at 0.001 level.

** Significant at 0.01 level.

(1) Only generations 4 to 23 .

(2) Significant at 0.10 level.

the reproduction system in these controls was modified from one male and female per family to five males and females per $20 \mathrm{p}$. Ioo of families taken at random. When regression from generations 4 to $23\left(C^{\prime}\right)$ is considered, a slight decrease was found, which confirms no important variation in failures in these populations when the system of reproduction was the properly one ; values for the first three generations were also discarded in $C^{\prime}$ due to some irregularities inherent to the beginning of the experiment.

\section{Fitness evaluation at the present level of selection. Short mating period}

A second study was carried out, in this case only with $A, B$ and $C$ populations, at the present level of selection (i.e. 35 generations of $A$ and $C$ and 29 of $B$ ). From samples of each line and replication of these populations, a certain number of single pair matings were made, and after 48 hours the male and the female in each vial were removed, so that only the egg laying of such two days was allowed to hatch 
and develop. At 3 weeks of mating (I9 days after removing adults) the offspring in each vial was counted considering the total figure of individuals and the relative proportion of larvae, pupae and adults.

Data for this evaluation are in table 4 , which includes percentage of matings failed, total number of individuals per family in terms of total and of successful matings, and finally the data of precocity. From more than 500 matings in each selection type $27 \mathrm{p}$. IOo in $B$ and $29 \mathrm{p}$. Ioo in $A$ failed totally whilst in the controls only $8 \mathrm{p}$. roo were lost. In total number of individuals, $A$ presents a little better situation than $B$, with I 8 and $\mathrm{I} 3$ per successful mating respectively, but both are really lower than the control figure of 24 (having similar proportion when figures per total matings are taken). The controls also present excellent precocity with 42 p. roo of adults and only 2 p. Ioo of larvae, compared with that of selected populations where $A$ seems to be worst than $B$ with 8 p. roo vs. 2 I p. Ioo of adults respectively.

TABLE 4

Some measures of fitness traits at 19 days after $4^{8}$ hours of mating

Mesures de caractères de valeur adaptative à 19 jours après 48 heures d'accouplement

\begin{tabular}{|c|c|c|c|c|c|c|c|}
\hline \multirow{2}{*}{ Populations } & \multicolumn{2}{|c|}{ Matings } & \multicolumn{2}{|c|}{$\begin{array}{l}\text { Number of individuals } \\
\text { per matings }\end{array}$} & \multicolumn{3}{|c|}{$\begin{array}{c}\text { Precocity } \\
\text { Percentage of }\end{array}$} \\
\hline & Total & $\begin{array}{c}\text { Failed } \\
(\%)\end{array}$ & Total & Successful & $\begin{array}{c}\text { Larvae } \\
(\%)\end{array}$ & $\begin{array}{c}\text { Pupae } \\
(\%)\end{array}$ & $\begin{array}{c}\text { Adults } \\
(\%)\end{array}$ \\
\hline$A$ & 538 & 29 & 12.90 & $18.16 \pm 0.52$ & 7 & 85 & 8 \\
\hline$B$ & 550 & 27 & 9.19 & $12.67 \pm 0.40$ & 4 & 75 & 21 \\
\hline$C$ & 503 & 8 & 21.70 & $23.60 \pm 0.56$ & 2 & 56 & 42 \\
\hline
\end{tabular}

Fitness evaluations during the last generations. Long mating period

Data in table 5 are similar to those in table 4 , but they contain also information from $R / S$ and $s R / r S$ populations and they were obtained in some different way. In this case, regular matings of the selection program were considered and the sexing day individuals per vial were counted. In these regular matings, both male and female are not removed until 9 days after the mating, and even in some cases they are not removed at all ; so there is a long period of laying and many more eggs were allowed to hatch and develop than in the former evaluation. Measures were taken during the last three generations, but due to the different systems of reproduction for the several populations and given that this study was not the main objective, but only an additional research, the number of families evaluated are very different when comparing those population types; however, it was possible to draw a lot of information which proportionates quite enough accuracy. In this table the precocity is measured only by the percentage of larvae and, for a better information, average number of eggs obtained in the selection test is also included. 
Percentages of failed matings in $A$ and $B$ are also larger than for $C$ (I9 p. Ioo and I7 p. IOo vs. 6 p. Ioo respectively), but all these figures are smaller than those in table 4 , due probably to the greater chance which the female has to produce fertile eggs when having more than two days for laying. There are less failures in the r.r.s. than in $A$ or $B$, but more than in $C$, being this result in accordance with the lesser intensity of selection (only $I 7$ generations) and the smaller response as yet obtained.

TABLE 5

Some measures of fitness traits at $2 \mathbf{I}$ days after mating, along with the selected character.

Male and female removed 9 days after the mating

Mesures de caractères de valeur adaptative à 21 jours après l'accouplement, en parallèle avec le caractère sélectionné.

Mâles et femelles enlevés 9 jours après l'accouplement

\begin{tabular}{|c|c|c|c|c|c|c|}
\hline \multirow{2}{*}{ Populations } & \multicolumn{2}{|c|}{ Matings } & \multicolumn{2}{|c|}{$\begin{array}{l}\text { Number of individuals } \\
\text { per matings }\end{array}$} & \multirow{2}{*}{$\begin{array}{c}\text { Percentage } \\
\text { of larvae } \\
(\%)\end{array}$} & \multirow{2}{*}{$\begin{array}{c}\text { Virgin female } \\
\text { egg laying } \\
\text { average }\end{array}$} \\
\hline & Total & $\begin{array}{c}\text { Failed } \\
(\%)\end{array}$ & $\begin{array}{c}\text { Total } \\
\text { matings }\end{array}$ & $\begin{array}{l}\text { Successful } \\
\text { matings }\end{array}$ & & \\
\hline$A$ & 843 & 19 & 60.30 & $74.21+1.58$ & 53 & $88.67+1.07$ \\
\hline$B$ & 500 & 17 & 64.55 & $77.40 \pm 1.86$ & 48 & $0.33 \pm 0.07$ \\
\hline$C$ & 800 & 6 & 105.16 & $111.73 \pm 1.28$ & 40 & $17.11 \pm 0.34$ \\
\hline$R / S$ & 164 & 13 & 83.96 & $93.67 \pm 3.18$ & 71 & $73.02 \pm 1.73$ \\
\hline$s R / r S$ & 989 & 14 & 81.08 & $94.34 \pm 1.15$ & 35 & $72.94 \pm 0.65$ \\
\hline
\end{tabular}

When observing the individuals obtained, both in a total as well as in a successful mating basis, it is found a very similar pattern than before in the sense that $A$ and $B$ have the smallest number, $C$ the largest and $R / S$ and $s R / r S$ intermediate figures. As expected, because of the longer period of lay allowed to the female, figures for total number of individuals here are much greater than in table 4 .

In precocity, also $A$ results slower than $B$ and both worse than $C$. However, it is interesting to note that in the r.r.s. the crosses have the best figure of precocity, even better than the controls, and the pure lines the worst; suggesting some clear effect of heterosis for this character. It is normal that in table 5 the percentages of larvae be greater than in table 4 because many larvae found the sexing day should have hatched a few days before, in contrast with those from the special mating of only 48 hours.

\section{Correlations among fitness traits and selected character}

Some correlations were calculated between figures of the selected character, virgin females laying, and two of the fitness traits, namely, number of individuals per mating and percentage of larvae when sexing, using the same data of the last three generations used for the evaluations on table 5. Correlations between both 
fitness traits were also obtained. Correlation coefficient values and their standard errors with the indication of a possible statistical significance are in table 6 .

The first egg laying figure utilized was the average for five sisters in the same family or mating where the two fitness traits were evaluated, $i . e$. it was really the figure of the regular tests for evaluation of lines in the selection experiment. The correlations estimated in this way are those listed in the table as $(r)$. No significant values were obtained for correlations between the fitness traits $\left(r_{x z}\right)$. However, there are significant values in correlations between both of them and egg laying $\left(r_{x y}\right.$ and $\left.r_{z y}\right)$ in the selected lines, with only one exception $\left(r_{x y}\right.$ for $\left.s R / r S\right)$, but not in the controls.

\section{TABLE 6}

Correlations between number of individuals per successful mating (X), percentage of larvae $(\mathrm{Z})$ and egg laying average $(\mathrm{Y})$

Corrélations entre le nombre d'individus par accouplement réussi (X), le pourcentage de larves $(\mathrm{Z})$ et la ponte moyenne $(\mathrm{Y})$

\begin{tabular}{|c|c|c|c|c|}
\hline Populations & $r_{x y} \pm \sigma_{r}$ & $\mathrm{~F}$ & $r^{\prime} x y \pm \sigma_{r}$ & $\mathrm{~F}$ \\
\hline $\begin{array}{c}A \\
B \\
C \\
R / S \\
s R / r S\end{array}$ & $\begin{array}{l}0.14 \pm 0.04 \\
0.14 \pm 0.05 \\
0.00 \pm 0.04 \\
0.20 \pm 0.09 \\
0.02 \pm 0.04\end{array}$ & $\begin{array}{l}12.52^{* * *} \\
7.40^{* *} \\
0.01 \\
5.31 * \\
0.22\end{array}$ & $\begin{array}{c}0.03 \pm 0.04 \\
- \\
0.00 \pm 0.04 \\
0.18 \pm 0.08 \\
0.06 \pm 0.04\end{array}$ & \begin{tabular}{l}
0.60 \\
\multicolumn{1}{c}{} \\
0.00 \\
$4.81^{*}$ \\
$3.24(1)$
\end{tabular} \\
\hline & $r_{z y} \pm \sigma_{r}$ & $\mathrm{~F}$ & $r_{z y}^{\prime} \pm \sigma_{r}$ & F \\
\hline $\begin{array}{c}A \\
B \\
C \\
R / S \\
s R / r S\end{array}$ & $\begin{array}{l}-0.08 \pm 0.04 \\
-0.11 \pm 0.05 \\
-0.01 \pm 0.04 \\
-0.21 \pm 0.09 \\
-0.10 \pm 0.04\end{array}$ & $\begin{array}{l}3.69\left(^{1}\right) \\
4.33^{*} \\
0.06 \\
5.91^{*} \\
7.78^{* *}\end{array}$ & $\begin{array}{r}0.07 \pm 0.04 \\
- \\
-0.04 \pm 0.04 \\
0.17 \pm 0.08 \\
-0.05 \pm 0.04\end{array}$ & $\begin{array}{l}3.35\left({ }^{1}\right) \\
1 . \overline{16} \\
3.79\left(^{1}\right) \\
2.09\end{array}$ \\
\hline & $r_{x z} \pm \sigma_{r}$ & $\mathrm{~F}$ & & \\
\hline $\begin{array}{c}A \\
B \\
C \\
R / S \\
s R / r S\end{array}$ & $\begin{array}{l}-0.02 \pm 0.04 \\
0.06 \pm 0.05 \\
0.04 \pm 0.04 \\
0.01 \pm 0.09 \\
0.02 \pm 0.03\end{array}$ & $\begin{array}{l}0.20 \\
1.41 \\
1.47 \\
0.00 \\
0.30\end{array}$ & & \\
\hline
\end{tabular}

Significant at 0.001 level.

** Significant at 0.01 level.

* Significant at 0.05 level.

(1) Significant at 0.10 level. 
better that deterioration, Figures $6,7,8$ and 9 present those results in a schematic way. Figure 6 gives simply the slopes of the regressions, and Figures 7,8 and 9 have on the vertical scale the value for the measured trait and on the horizontal one

9 DAYS MATING
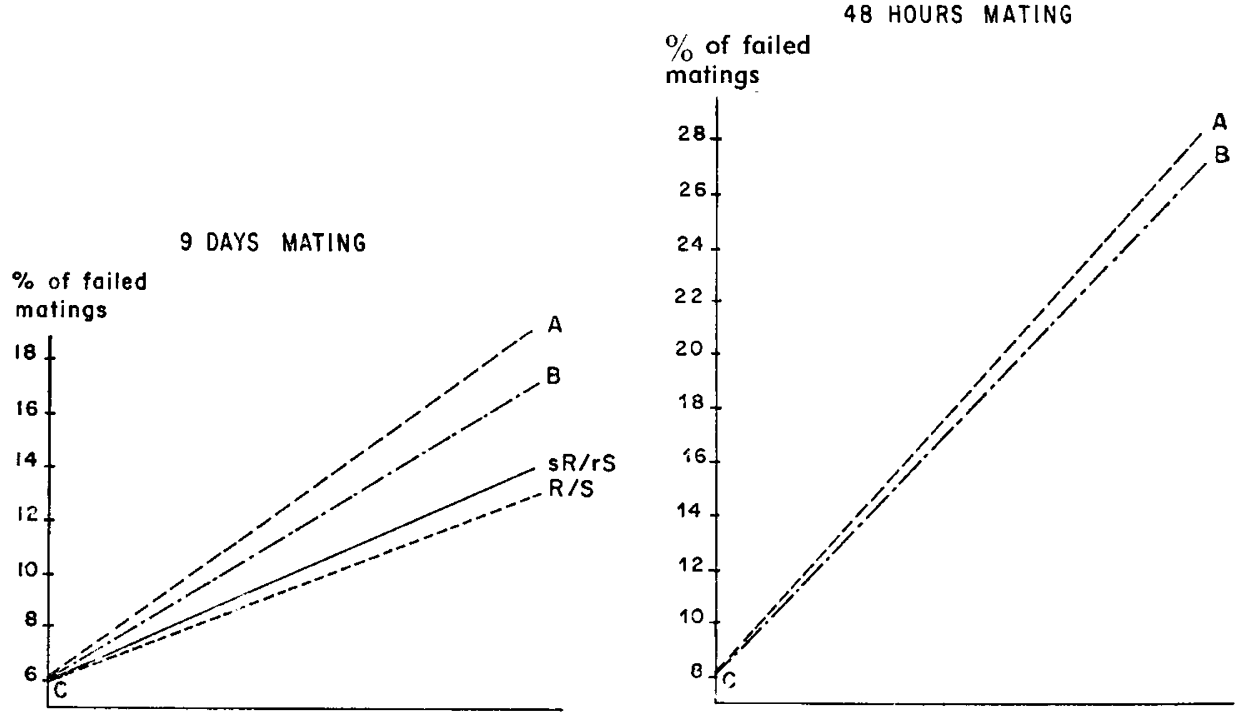

Fig. 7. - Percentage of failed mating

Pourcentage d'accouplements n'ayant pas abouti

TOTAL MATINGS
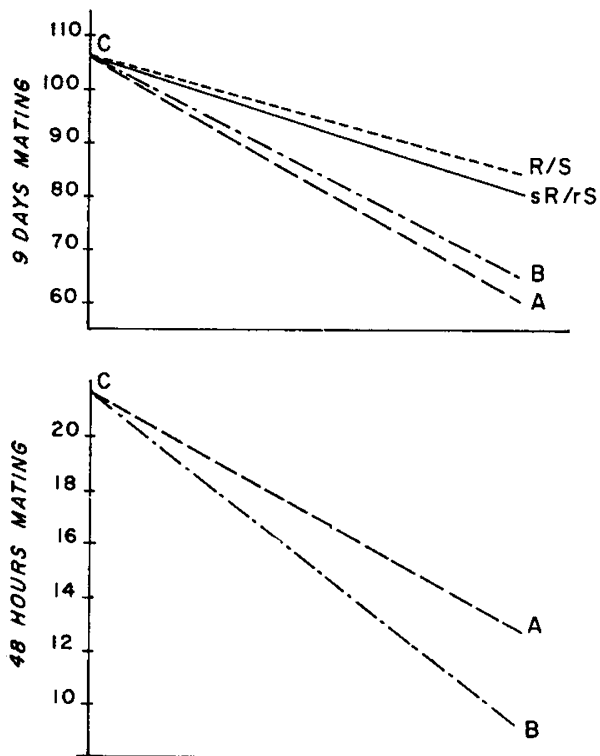

SUCCESSFUL MATINGS
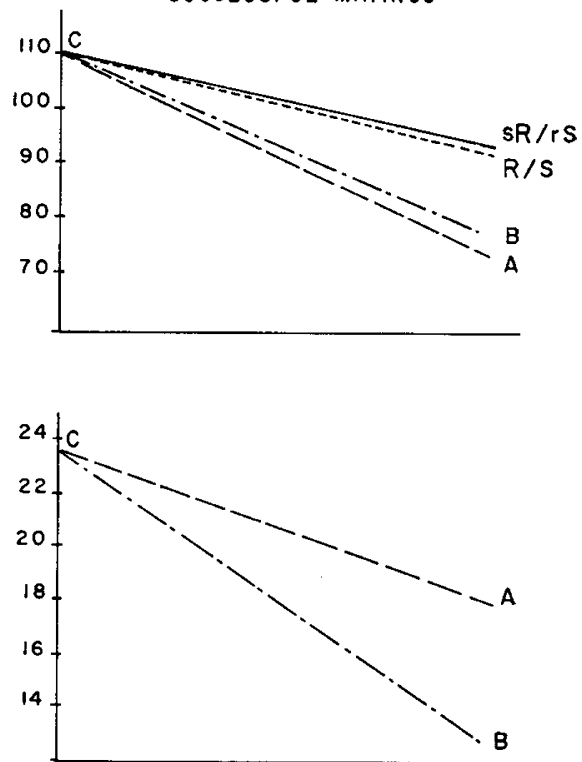

FIG. 8. - Number of individuals per mating Nombre d'individus par accouplement 
there are only two points : at left the original population before selection, as measured by the controls, and at right the selected populations. Following these graphics it is possible to do some more comments on the three fitness traits considered.
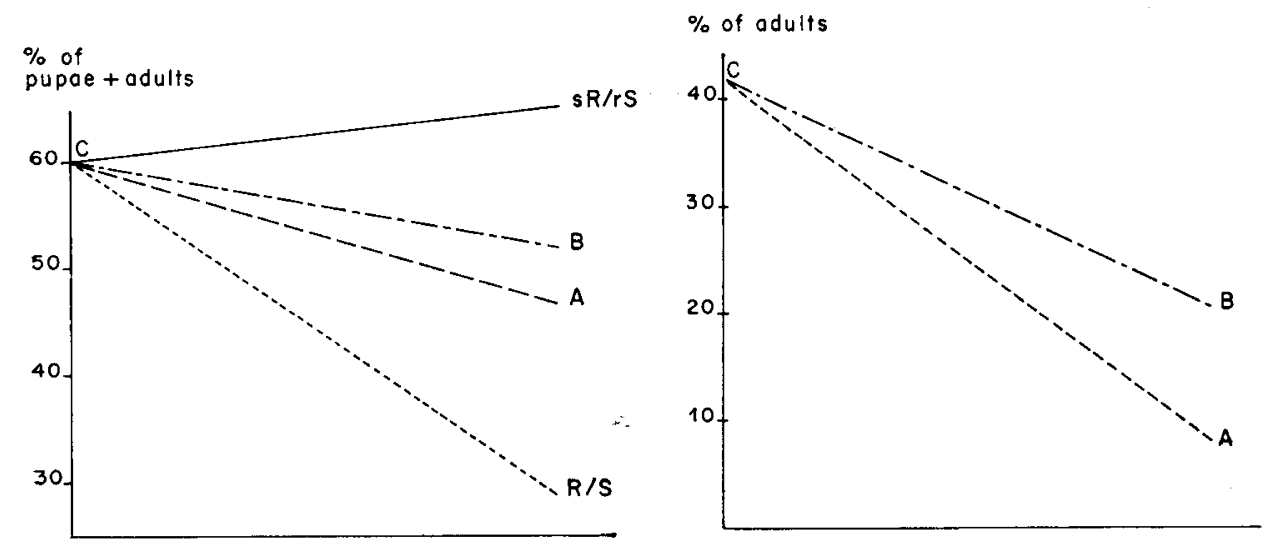

FIG. 9. - Precocity of development

Précocité du développement

\section{Proportion of failed matings}

This trait measures mainly fertility, even though it could include other components of the fitness as hatchability, mortality, etc. It is unquestionable that it has increased significantly when different populations were selected and in all cases it presents figures larger than the control ones. Values intermediate for the r.r.s. lines, as seen in figure 7 , are reasonable because they were submitted to only half number of generations of selection and so the response has not been as important as in $A$ or $B$.

When measuring this deterioration as a regression on generations, the loss in $A$ becomes smaller because the absolute figure is reduced here to an " on generation basis " value. Pure lines of r.r.s. present worse coefficient than crosses, so it could be a sign of heterosis in these crosses and of weakness in those pure lines; this is also obvious because due to the reproduction system, some more inbreeding must be expected in r.r.s. pure lines than in the $A$ or $B$ ones. It is interesting to note, when considering data of figures 6 and 7 , that they are not completely comparable, in the sense that the regression values took into account the data in all generations and the other evaluations only consider the last two or three generations.

Regression of failures on egg laying confirmates that pure lines in r.r.s. are worse than crosses ; and the latter ones are here even better than $A$ lines when considering the deterioration of this trait per unit of egg laying, though this difference is not significant as it is seen from the standard errors. The slope for $B$ can not be compared with those above mentioned because selection to decrease egg number with a physical limit of zero eggs, starting with figures around $\mathrm{r}_{5}$ eggs, necessarily produce larger percentage of failures per unit of egg number response; the total response is very important, but the scale must be different for comparisons with $A$ and r.r.s. 


\section{Precocity}

Deterioration seems to be worse in $A$ than in $B$, but the most important point here is the great difference between pure lines and crosses in the r.r.s. Values for the pure lines are the worst for all populations considered and, however, those for crosses are even better than the control ones. So there is a clear situation of heterosis in the speed of development of larvae when they are hybrids and a slowing process with the pure lines.

It is interesting to note that if it is more or less questionable to consider precocity of larvae development as related or not with fitness, in this experiment, however, it must be considered so because there is an exact schedule for the different operations, with sexing performed exactly at $2 \mathrm{I}$ days after mating; and therefore, any family with less than five female pupae results handicapped and thus natural selection plays its role. In fact, $A$ and $R / S$ present more difficulties to get enough sexed pupae, and during the last generations some decisions had to be taken, mating some lines one or two days earlier, in order to prevent the destruction of the line ; this changes a little the experiment but it was preferable to take this step, knowing its consequences, that to lose lines.

\section{Number of individuals per mating}

This trait, when is considered from the successful matings, gives probably a measure of the fecundity of females mated, plus hatchability and, of course, livability of larvae during the development stage, without discarding the possibility, even small, of the fertility taking also part on it. In this way, if percent of failed matings contained likely the major part of the fertility deterioration with some portion of the hatchability, this number of individuals at sexing must be more important to evaluate egg laying of fecundated females and livability of larvae offspring.

It is also clear that selection response has taken also its toll in this trait, presenting similar pattern than in the other evaluated characters in the sense that plateaued populations have less number of individuals than those with a lesser response (r.r.s.). In this case, however, there are not symptoms of heterotic effects in the crosses when compared with pure lines.

Egg laying of fecundated females plays an important role in the total number of individuals per mating evaluated here, as it is demonstrated observing that when male and female were removed after 48 hours of mating, the figure in $B$ is much smaller than in $A$, but when they were maintained a longer period, $B$ had more time to compensate for the smaller laying rate and so there were not significant differences with $A$. Evidently, in this case something must have happened with $A$ offspring in order to get no more individuals than $B$; probably, though only in part, the well known fact that females no longer lay many more eggs when there are already a large offspring, perhaps competition and canibalism, but most surely because there was a higher mortality in $A$ than in $B$. This is confirmed when looking at he r.r.s. and $C$ values with higher final figures, since the vial for larvae development is a large one with enough amount of flour to sustain a great number of larvae. Therefore, at this moment, we may conclude that deterioration in $A$ lines is probably due more to larvae mortality and less to laying rate of the female whilst in $B$, even though the 
mortality probably also played its role, is more important the reduced egg laying of females, compensated or not with a longer or smaller mating period.

Comparing right and left sides of figure $8, i$.e e, number of individuals per total or per successful matings, it is deducted that fertility, as measured by the failed matings, has not had an important discriminated part in the total number of individuals per se; mainly when comparing systems of selection as three important groups $(C ; R / S$ and $s R / r S ; A$ and $B)$ and looking for their ranking order.

\section{Comparing intended vs, realized selection differentials}

A measure of the action of natural selection against artificial selection can be obtained comparing the intended or applied selection differential with the realized one, $i$. e., with that obtained weighing the first one with the offspring number per family which really were evaluated in the following generation.

\section{TABLE 7}

Difference between intended $(i)$ and realized $\left(i^{\prime}\right)$ selection differentials Différence entre les " sélections différentielles "voulues (i) et réalisées $\left(i{ }^{\prime}\right)$

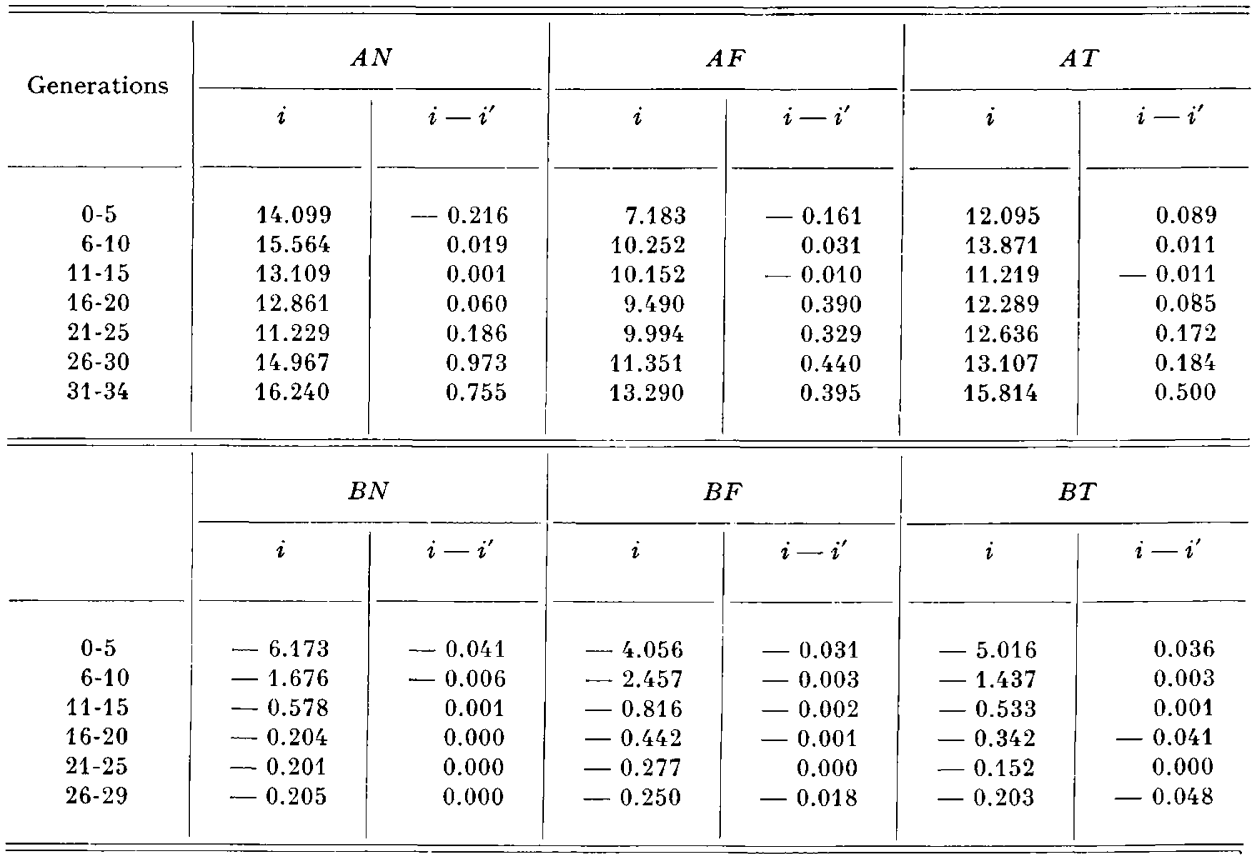

The discrepancy, in this experiment, is no expected to be very large, at least during the first generations, because 5 females were picked up from the many more existent per family, and so the effect of such natural selection is not the same as it would be if proportional figures to the offspring numbers were left to reproduce them- 
selves. That discrepancy can be only detected when, because of the selection process and its consequent fitness deterioration, that number becomes smaller and there be families with less than those five females, even as when total families be lost. Because of the complication of the interpretation which represents this evaluation on the r.r.s. and to simplify the presentation, only populations $A$ and $B$, with the greatest response, have been considered. Table 7 gives the intended values and those discrepancies, pooling replications and making groups with five consecutive generations averaged.

In $A$ populations, even though the total discrepancy at the end is not very large, as compared with the intended " $i$ ), there is a clear tendency to appear between generations $16-20$ and to grow up toward the end. So it is possible to conclude that in spite of the restriction of taking only five females per family, from the total number alive, there is a clear indication that natural selection is acting against the artificial one intended, though that effect have not been drastic.

As expected, in $B^{\prime} s$ this effect does not appear, because when the response is considerable and failures in the offsping could be seen, all the selected females had zero laying and so both selection differentials are identical. Negative discrepancies indicated here the antagonistic effect investigated and thus it is possible to see that during the first generations, at least in $B N$ and $B F$ lines, some effect did exist in a subtle way.

Also, in this discussion of natural vs. artificial selection it is worthwhile to comment the results of correlations obtained between two fitness traits and the selected character, included in table 6 ( $r^{\prime}$ values). The interpretation of such values, however, must be done with caution because they are not really genetic correlations, even though they are neither purely phenotypic correlations given that in some cases they include sibs averages; moreover, percent of larvae is a special trait to treat with statistically; and finally, when egg laying of females mated was included in the calculations, the male contribution to the fitness of the offspring, was not considered.

However, it is clear that : no close relations seems to exist between both fitness traits. Egg laying does not show up to be related with precocity nor total number of individuals per mating in the base or unselected population according to the results of the control lines. In $B$ type of selection a definite antagonism has been produced between the selected character and these two fitness traits due to the drastic selection to decrease egg laying. In r.r.s. the antagonism appears only with precocity in pure lines but not with crosses, probably because of the heterotic effect found and named above ; and with number of individuals the two positive figures could indicate that, due to the lesser selection response at the present, there is not as yet such a confrontation in a great extent, as it is seen in the figure 8 . With $A$ type of selection a clear antagonism also appears, but only when considering precocity.

As far as the relation with number of individuals in $A$ lines is concerned, the $\boldsymbol{r}^{\prime}$ is practically zero. If it were really zero, it could be explained considering that an equilibrium has been attained at the present level (generation $35^{\text {th) }}$ where no more reduction is being done in number of individuals per mating to the expenses of a non-response in the selected character; without discarding the possibility that a true genetic correlation estimate could produce a negative value, since it has been clearly shown the drastic reduction of that number of individuals. 


\section{Egg laying of fecundated females}

Unfortunatelly, measures of this trait have not been taken at the present level of the experiment, but due to be very interesting for a deep investigation in the topic of this work, they will be obtained probably sometime during the next generations.

However, there are some references from other experiment (FUENTES, I969) based on measures of that trait at the level of the generation 25th in $A, B$ and $C$ populations. In lines $N$ and $F$ of such populations, ten females per each family were tested for egg laying ; five were virgin and five fecundated. Average egg laying figures as well as direct and correlated responses after those 25 generations of selection for virgin egg laying, along with some genetic correlation estimates between both traits, are in Table 8 .

TABLE 8

Data of egg laying of virgin (selected trait) and of fecundated females, direct and correlated responses, and genetic correlations between both characters, at generation 25

Données de ponte des femelles vierges (caractère sélectionné) et des femelles fécondées, réponses directes et liées, et corrélations génétiques entre les deux caractères, à la génération 25

\begin{tabular}{|c|c|c|c|c|c|c|}
\hline \multirow{2}{*}{$\begin{array}{c}\text { Populations } \\
\text { and } \\
\text { lines }\end{array}$} & \multicolumn{2}{|c|}{ Egg laying of females } & \multicolumn{2}{|c|}{ Response to selection } & \multicolumn{2}{|c|}{ Genetic correlation } \\
\hline & Virgin & Fecundated & Direct & Correlated & Realized & $\begin{array}{l}\text { Estimated by } \\
\text { sibs analysis }\end{array}$ \\
\hline$A N$ & 85.07 & 96.27 & 67.03 & 37.71 & $0.25-0.30$ & 0.89 \\
\hline$C N$ & 18.04 & 58.56 & - & - & - & 0.64 \\
\hline$B N$ & 0.34 & 25.09 & 17.70 & 33.47 & $0.70-0.75 ?$ & 0.05 \\
\hline$A F$ & 48.18 & 56.11 & 37.22 & 40.39 & $0.50-0.55$ & 0.82 \\
\hline$C F$ & 10.96 & 15.72 & 一 & - & - & 0.80 \\
\hline$B F$ & 0.25 & 2.81 & 10.71 & 12.91 & $0.60-0.65 ?$ & -0.02 \\
\hline
\end{tabular}

From this very definite correlated responses, it is clear that genetic correlation between those two traits in the unselected base population had to be positive. Calculations of realized values for that correlation obtained from those responses are also included in that table giving reasonably high positive figures for $A$ lines. The estimates for $B$ are not dependable because it is very questionable to apply to this special type of response the same $h^{2}$ of the base population, given the fact that after few generations $B$ data follow a distribution away from the normal one.

Average of several estimates of this genetic correlation by sibs analysis at that $25^{\text {th }}$ generation gave the values listed at the end of the table, which though for $A$ and $C$ they are very high, due probably to be inflated by dominance and other nonadditive effects, as it is well known it happens in this type of analysis, at least they give a clear picture of the situation at that level of 25 th generation : populations $A$ still maintain positive, and probably quite high, genetic correlations, whilst selec- 
tion for low laying has produced such an effect as to decrease it, reaching to nearly zero. This latter effect was expected because in other way $B$ lines would have disappeared or no response would had been obtained, after some few generations, due to the contrary force of natural selection (less lay in fecundated females).

Finally, it would be interesting to compare laying rate of fecundated females at generation 25 with the present situation in order to see if that trait has evolutioned, and in which direction, during the last generations. Having no evaluation of such a trait at the present level, the number of individuals per successful mating after 48 hours has been considered as an indication of the possible laying rate, with the understanding that it includes also a portion of hatchability and livability failures. In order to be compared with the egg laying, tested always in 4 days, the number of individuals value has been multiplied by two. Given that only $N$ and $F$ type of lines were measured in generation 25, data for only these two lines in the offspring counts have been considered. The average figures are :

\begin{tabular}{ccc} 
Populations & $\begin{array}{c}\text { Egg laying at } \\
\text { generation } 25\end{array}$ & $\begin{array}{c}\text { Individuals per mating } \\
\text { at present level }\end{array}$ \\
\hline A & - & - \\
B & $9 \mathrm{r} .69$ & $34.0 \mathrm{I}$ \\
C & I7.16 & 24.04 \\
& 49.25 & 45.55
\end{tabular}

These figures are really interesting because in $C$, where egg laying must have continued alike from $25^{\text {th }}$ to $35^{\text {th }}$ generations, the small difference of 3.70 is due probably to a reduced rate of mortality plus hatchability reasonably expected in these control populations. In the $A$ lines the drastic reduction must be due mainly to mortality and hatchability, as it was deducted when commenting " number of individuals " deterioration; though it could have also had some reduction in the egg laying of fecundated females as a correlated response to the pressure, during the last ro generations, on the virgin egg laying, contrarily to that found during the first 25 generations. The increase of 6.88 in the $B$ populations, considering that some mortality or failures in hatchability must have occurred also, tells that during the last generations the suspected zero or negative correlation has really gone to negative figures and some increase in egg production of fecundated females has followed. The estimation of this parameter in the future, from next generations data, will help to interprete if that was so or not.

\section{General comments and conclusions}

Looking at the totality of the results presented before, it seems worthwhile to compare them with other from more classical works or findings related with the topic studied here :

The selected character, egg laying of virgin females, is positively correlated with egg laying of fecundated females in the base original population and thus it could be considered in some way as a fitness component. However, it has been shown that it is not really a fundamental component, or component per se, because when selection was directed for low laying, the response was so good that in few generations mean values around zero were obtained in each $B$ line, with a great 
percentage of females laying no eggs during the four-days testing period. The genetic correlation between those two traits has decreased toward zero and even there are reasons to think that at the present level it could be negative. If the selected trait had been a real fitness component, no response would have been obtained after a few generations due to the heavy losses of offspring in selected females; so more and more diminishing selection pressures would have been applied on those $B$ lines. This is the same as to say that if the genetic correlation had remained statically with high positive values, the selected females after fecundation would have laid less and less eggs, or even no eggs at all, with the consequent drastic loss of many complete families. On the other hand, the correlated response found at generation 25 induces to think that either the decreasing trend of the genetic correlation going down to zero must have been a quite slow process, but persistent, or rather that correlated response was obtained during the early generations, the gains persisting until the 25 th, if the genetic correlation became quickly zero maintaining this value until that testing generation.

Selection for high laying should not change that positive genetic correlation because that selection would be accompanied by a positive increase of egg fecundity which is a real component of the fitness. This has been shown by some estimations of that correlation in $A$ lines in generation 25 and because of correlated responses of fecundated females. Probably during last generations improvement in this unselected trait has been smaller or even null; but doubtless it is possible to say at the present that good virgin laying is accompanied by good fecundity, contrarily to the situation found in $B$ lines.

Analyzing some fitness components, such as percent of failed matings, number of individuals obtained per mating and precocity of larvae development, it was possible to verify that these traits were deteriorated during the process of selection in all types of populations compared with the unselected controls. Largest deterioration was found in $A$ and $B$ types, with 35 and 29 generations of selection respectively and with a practical plateau situation on both, though the $B$ plateau is different to the $A$ one because of its physical limit of zero laying. Populations under r.r.s. present that deterioration but, in general, at lesser levels, probably because they are really at the present in the I 7 th generation of selection and no plateau seems to exist as yet. In two cases, precocity and percent of failed matings, some clear heterotic effect is showed up when comparing pure lines vs. crosses in this last type of selection; being in precocity so strong that crosses are even better than controls.

From the results in $B$ lines, the selected trait must be considered as neutral or at least peripheral to fitness, and therefore that deterioration of the three particular reproductive traits analyzed here in all selected populations must be explained by the antagonistic effect of natural selection though not by a direct action as when a negative genetic correlation exists, but rather through some kind of indirect and unknown process of equilibrium loss in the physiologism. It is obvious that when there is a fitness deterioration natural selection is acting against artificial selection, but it is the purpose all over this presentation to distinguish, as stated formerly in the introduction, between two different actions : If the selected trait is negatively correlated with a clear fitness component the effect of natural selection acts immediatelly. But, if in the beginning there is not a clear situation of negative correlation and the selection responds well during several generations, something happens after- 
wards to the relationship between that selected trait and some fitness components either because that correlation becomes negative or due to another kind of action which permits also the natural selection to play its role.

Before passing to discuss some possible explanations to that fitness deterioration, two experiments with chickens will be commented here taken from the several reports related with the results found in this work, $i$. e., where the selection was directed to a neutral or peripherical trait to fitness.

One is the selection for " comb blades" reported by TAYLOR (I946) later on summarized by LERNER (I954). In few years the population of chickens became composed only of birds 3, 4 or 5 blades, but the response to the selection was stopped because, to maintain the line, individuals with 3 and 4 blades should be used for reproduction, along with those with 5 , due to the fact of the low reproduction rate in these 5 blades birds.

Also, it can be considered as a classical example that given by LERNER (I958) on chickens "shank length ", where the trait neither seems to be directly related with fitness. In one of his interesting conclusions he says : "The results obtained in the later generations suggest that in them opposition of natural selection to artificial selection arose. This was a dynamic response of the population to the pressure applied and not the consequence of a purely static relationship between the character selected for and fitness."

This dynamic aspect of the genetic parameters as modified by the fact of the selection has appeared clearly, as stated before, through the evolution of the egg laying of fecundated females as related with the virgin females laying in the $B$ populations, changing the genetic correlation from positive to zero and even to negative values. On the contrary, the genetic correlation between the selected character and the three fitness traits evaluated here has to have changed from practically zero to negative figures; being this fact in line with RoBERTSON's (I955) thiniking in the sense that given a peripherical character, selection itself alters its position in relation with fitness becoming a major component of it.

The best explanation for that position change of virgin laying as related with fitness must arrive from this known argument : in the base unselected population, with fitness at an optimum, the expression for that character evaluated in four days is about $I 5-20$ eggs, so any change on it going far from this figure, probably disturbs the equilibrium and therefore natural selection starts its action. As FAICONER (I960) states : "If a population is in genetic equilibrium it follows that a reduction of fitness must in principle result from any change in the array of gene frequencies, apart from any genes that may have not effect on fitness. Natural selection must therefore be expected to resist any tendency to change of the gene frequencies, such as must result from artificial selection applied to any metric character other than fitness itself. This principle has been called genetic homeostasis. Thus if we change any metric character by artificial selection we must expected a reduction of fitness as a correlated response. "

To understand the fact that selection for virgin laying produces that fitness deterioration, it helps to consider that to affirmate that a trait is not related with fitness is a very doubtful statement given the complicated physiological pathways acting in total. This was very good stated by LERNER (I958) when saying : "In natural selection, selective advantage is the property of the totality of all phenotypic 
expressions of the genotype, among which the decisive role as often as not is played by subtle differences at the physiological or biochemical level which cannot be discerned by the human observer and whose existence is often not suspected by him. "

Independently to other more or less plausible explanations to the topic discussed here there is also the well known fact of the greater fitness of the intermediate range of phenotypes, very good examplified, among many reports, by the data of LERNER and GUNNS (I952) and RENDEL (I943) with chickens and ducks respectively, on the relationship between egg weight and hatchability and other reproductive traits. Maximum for these traits is at intermediate values of egg weight, and only the average for such a weight was maintained a little over that maximum due to the constant pressure of directional selection. It is obvious, as in the comb blades example, that those individuals which present the selected character with the highest values, generally are sterile, defective, weaker, etc., $i$. $e$., they are less competitive.

It is not intended here to discuss the question of whether some phenotypes are more fit only because they correspond to intermediate phenotypes or because they are heterozygous, or even because of another more complicated physiological balance. But unquestionably, above all possible explanations for that fact, there is a very clear fact : the impossibility to create monsters going with any character over certain reasonable limits. It is like in the physical world : a piece of rubber can be stretched more and more (genetic variability), but after some limit it is not possible to lengthen it because the molecules dont' allow it (variability is exhausted), but if, in spite of it, later on it is pretended to pass, that piece is broken (fitness deterioration).

Therefore, in the list of the reasons to explain the limits to the selection, or plateaus, together with some very important ones, as loss of variability, selection for several incompatible traits, direct contrary action of natural selection, etc., it is also necessary to consider this subtle but definite action of reproductive deterioration when any quantitative character, apparently no related with fitness, is selected towards extreme limits.

\section{RÉSUMÉ}

\section{INFLUENCE DE LA DÉTÉRIORATION DE LA VALEUR ADAPTATIVE SUR LES LIMITES DE LA SÉLECTION}

Après avoir passé en revue les principales causes et les solutions possibles des " plateaux" de sélection, et compte tenu du ralentissement des réponses dû à la perte de variabilité lorsque la sélection progresse, nous considérons l'importance de l'action de la sélection naturelle et de la relation entre valeur adaptative et limites de la sélection, avec la création, dans de nombreux cas, d'individus non équilibrés lorsqu'un critère étroit est utilisé dans une sélection pour des caractères de production spécifiques.

A partir des données d'une expérience pilote de sélection de longue durée sur Tribolium castaneum comparant des systèmes de sélection en relation avec les interactions génotype-environnement, une étude a été entreprise des relations entre les caractères de reproduction ou d'adaptation (fitness) et la réponse à la sélection ou ses limites. Après avoir présenté la réponse de chaque lignée sélectionnée et montré sa situation du point de vue de la possibilité d'un " plateau ", nous avons recherché l'influence du niveau de performance du caractère sélectionné — oviposition des femelles vierges - sur le pourcentage de familles et d'individus, par rapport au total des accouplements, qui ne se reproduisaient pas ou ne survivaient pas jusqu'au stade adulte. Cette étude a consisté en une régression de tels pourcentages à la fois sur les générations de sélection et sur la ponte moyenne dans la génération et la population correspondante. 
D'autre part, aux générations 33 à 35 , le nombre de larves, de pupes et d'adultes par famille, à une date spécifiée après l'accouplement, a été enregistré pour obtenir une estimation de la viabilité et de la précocité, ainsi que de leurs corrélations avec la ponte et entre elles, afin d'étudier leurs interrelations. Comme les populations témoins reflètent les valeurs originelles pour de telles relations, il a été possible d'en déduire leur évolution en comparant différents types de sélection et de populations plus ou moins en "plateau ". Certains contrastes intéressants ont été trouvés et sont discutés en détail.

Des comparaisons entre sélections différentielles recherchées et réalisées au cours des générations ont aussi été faites, en cherchant à analyser les effets de la sélection naturelle opposée à la sélection artificielle et discutant leurs implications sur les limites de la sélection. Cette étude complète l'information utilisée dans la discussion générale présentée à la fin.

Il est apparu clairement une relation étroite entre le niveau de performance du caractère sélectionné et les caractères d'adaptation étudiés, en ce sens que la sélection naturelle jouait, comme prévu, un rôle important de ralentissement des réponses à la sélection intentionnelle par l'intermédiaire d'une perte de la capacité de reproduction et de survie. En connection avec la sélection naturelle, deux types d'action ont été analysés, correspondant au cas où le caractère sélectionné est en corrélation négative avec la " fitness", et au cas où il ne présente apparemmen $t$ pas de liaison avec elle. Le deuxième point était le principal objet discuté ici, parallèlement aux résultats rapportés par d'autres auteurs, car il a été montré clairement, par l'évolution de la ponte chez les femelles fécondées que le caractère sélectionné jouait un rôle "périphérique "vis-à-vis de la " fitness ".

\section{REFERENCES}

Dickerson G. E., I955. Genetic slippage in response to selection for multiple objectives. Cold Spring Harbor Symposia Quant. Biol., 20, $213-224$.

FALCONER D. S., I960. Introduction to Quantitative Genetics. Oliver and Boyd. Edinburgh and London.

Falconer D. S., 1970. Breaking through a selection limit. 12 th British Poultry Breeders' Roundtable. Edinburgh (mimeographed).

Fuentes M. C., r969. Influencia de los cambios ambientales en la mejora genetica de aves de puesta, comprobados en el insecto Tribolium castaneum. (unpublished).

Lerner I. M., r954. Genetic Homeostasis. Oliver and Boyd. Edinburgh and London.

Lerner I. M., I958. The Genetic Basis of Selection. John Wiley and Sons, Inc. New York.

Lerner I. M., Gunns C. A., 1952. Egg Size and Reproductive Fitness. Poultry Sci., 31, 537-544.

Mérat P., r97ı. Utilisation de facteurs mendéliens en élevage : l'exemple de la Poule. Ann. Génét. Sél. anim., 3, 67-77.

Orozco F., r969. Comparing two systems of selection under environmental stresses and the problem of the genotype-environment interaction in Tribolium castaneum. Ph. D. Thesis. Purdue University, Lafayette, Indiana, U. S. A.

Orozco F., I97o. A pilot study with Tribolium of the influence of environmental stresses on genetic parameters and response to selection. Final Report, Research Project FG-Sp-I37 (U. S. D. A. PL 480 ). Inst. Nac. Investigaciones Agronómicas, Madrid, Spain.

Rendel J. M., 1943. Biometrika, 33, 48-58.

Robertson A., I955. Selection in animals : synthesis. Cold Spring Harbor Symposia Quant. Biol., 20, 225-229.

TAYLOR L. W., 1964. Multiplex Combs. Poultry Sci., 25, 6ro-6r5. 